\title{
Reseña
}

\section{Richard W. Merritt, Kenneth W. Cummins y Martin B. Berg (eds.). 2008. An introduction to the aquatic insects of North America, 4a edición. Kendall/Hunt Publishing Company, Dubuque, 1158 p. + CD con clave interactiva.}

\author{
Atilano Contreras-Ramos
}

Departamento de Zoología, Instituto de Biología, Universidad Nacional Autónoma de México. Ciudad Universitaria 04510 México, D. F., México. Correspondencia: acontreras@ibiologia.unam.mx

De los insectos se piensa comúnmente que son un grupo de invertebrados terrestres. En efecto, de 33 órdenes de hexápodos (para algunos autores, los apterigotos y entognatos Protura, Collembola y Diplura no son estrictamente insectos), sólo 13 tienen representantes acuáticos o semiacuáticos. También parece dominar la teoría de que los insectos se originaron en el ambiente terrestre (Lehmkuhl, 1979), aunque hipótesis recientes de parentesco con los crustáceos (Glenner et al., 2006) podrían apoyar un origen acuático. La gran mayoría de insectos asociados con el medio acuático viven en agua dulce, ya sea en lagos, ríos o arroyos, mientras que pocas especies se han adaptado a la vida marina, donde habitan ambientes litorales o flotan en la superficie del mar.

Así, en muestras de macroinvertebrados bentónicos de agua dulce, los insectos son un grupo conspicuo, de manera que los estudios de invertebrados de aguas epicontinentales tienen mucho que ver con la entomología acuática. Si se considera la importancia que tiene el agua dulce para la civilización actual, desde el punto de vista ecológico y de la diversidad biológica, los insectos acuáticos son un grupo fundamental, que se habrían de encontrar en estos delicados ambientes. Los insectos acuáticos constituyen un grupo polifilético unido para compartir el hábitat acuático.

No obstante la importancia de los ecosistemas de agua dulce, no hace mucho tiempo era difícil incursionar en aspectos taxonómicos básicos de estos grupos en un país megadiverso como México. Dada la cercanía con los Estados Unidos, obras elaboradas para la fauna neártica, como las de Usinger (1956), Edmondson (1959) y Pennak (1978), fueron grandes auxiliares, pero no fue sino hasta 1984, al publicarse la segunda edición de la obra reseñada, cuando pudo tenerse acceso a una colección de claves taxonómicas amplias y relativamente actualizadas, y a una perspectiva moderna del campo de la entomología

Recibido: 16 octubre 2009; aceptado: 04 mayo 2010 acuática. Poco antes, Hurlbert y Villalobos-Figueroa (1982) compilaron una colección de bibliografías taxonómicas que aún hoy es sumamente útil, pero que fue destinada a una función distinta, al no incluir claves o ilustraciones y por estar dirigida al trabajo especializado. La tercera edición del ya famoso "Merritt y Cummins" surgió en 1996, por supuesto revisada, pero la amplitud y calidad que alcanza la actual edición son muy superiores a las de aquella.

La tercera edición incluyó 26 capítulos en 862 páginas, con 41 autores; la obra actual también ofrece 26 capítulos, pero en 1158 páginas con 48 autores, manteniendo autoridades de primera línea. Además de la incorporación de un tercer editor, hay algunos cambios evidentes en la edición de 2008: la inclusión de un CD con claves interactivas, un glosario, 39 láminas a color y el incremento de 4652 referencias de la tercera edición a 5963 en la cuarta. Por tanto, la bibliografía de la obra es realmente un gran recurso para iniciarse no sólo en la taxonomía, sino también en la biología, ecología e historia natural de estos taxones.

Todos los capítulos fueron revisados; algunos sufrieron cambios mayores, incluso en autoría. De los capítulos introductorios, destacan por su amplia revisión el 3 (muestreo de insectos acuáticos), el 5 (historias de vida) y el 8 (filogenia). En lo personal, me parecen excelentes los capítulos 4 (respiración) y 6 (ecología), sobre 2 aspectos que describen mucho de lo especial de los insectos acuáticos, las adaptaciones respiratorias y sus estrategias de vida. En general, los capítulos 3 a 8 (muestreo, respiración, historia de vida, ecología, biomonitoreo y filogenia) pueden considerarse un libro de texto sobre entomología acuática, con amplias ramificaciones hacia la limnología y la ecología de ríos. La introducción (capítulo 1), presenta una breve historia, pero muy completa, de los principales trabajos que se han producido alrededor del tema de los insectos acuáticos norteamericanos, clasificados por su énfasis taxonómico o ecológico. El capítulo 2 (morfología) es una buena síntesis del tema, recomendable incluso para 
trabajo con insectos en general.

Los capítulos del 9 al 26 constituyen la parte taxonómica y substancial del libro. El capítulo 9 incluye una clave para órdenes, aplicable a estados inmaduros y adultos, además de un breve tratamiento sobre clasificación y claves. El resto de los capítulos se distribuye generalmente a través de los distintos órdenes, aunque alguno de éstos requirió mayor o menor atención: Collembola acuáticos (capítulo 10), Ephemeroptera (11), Odonata (12), Orthoptera semiacuáticos (13), Plecoptera (14), Hemiptera acuáticos y semiacuáticos (15), Megaloptera y Neuroptera acuáticos (16), familias de Trichoptera (17), géneros de Trichoptera (18), Lepidoptera acuáticos y semiacuáticos (19), Coleoptera acuáticos (20), Hymenoptera acuáticos (21), Diptera acuáticos (22, en 2 partes, larvas, y pupas y adultos), Tipulidae (23), Culicidae (24), Simuliidae (25) y Chironomidae (26); con los 4 últimos capítulos sobre familias de Diptera.

Resulta útil que al final de cada capítulo taxonómico se incluya una lista de referencias taxonómicas generales y regionales, así como por grupo menor; también se incluye un cuadro donde se lista cada género con el número de especies neárticas entre paréntesis, su hábitat, hábitos, papel trófico, distribución neártica, valores de tolerancia, así como referencias ecológicas. La distribución geográfica puede dar una buena idea sobre si se ha llegado a una identificación posible o improbable.

En cuanto a la efectividad de las claves, en particular para la fauna de México, esta obra ofrece un excelente apoyo en el nivel de género. Podría afirmarse, no obstante su enfoque neártico, que actualmente este libro es el primer recurso para la entomología acuática en el país. Sin embargo, no debe soslayarse que el componente neotropical y endémico de México demanda complementar la identificación de varios grupos con obras y artículos especializados sobre la fauna nacional. Evidentemente, si un estudioso de los insectos acuáticos se especializa en algún orden en particular, deberá profundizar en la literatura pertinente para el grupo en cuestión. Con mayor razón, no hay escapatoria a corroborar las identificaciones.

Pueden señalarse varios trabajos de cobertura mesoamericana que incluyen claves, para Ephemeroptera (Edmunds et al., 1976; McCafferty et al., 1997), Odonata (Novelo-Gutiérrez, 1997a, b), Megaloptera (ContrerasRamos, 1997) y Coleoptera (Arce-Pérez y Roughley, 1999), que aunados a capítulos de síntesis en la serie de artrópodos de México (Llorente-Bousquets et al., 1996, 2000, 2004; Llorente-Bousquets y Morrone, 2002) facilitan adentrarse en la sistemática de los grupos acuáticos de México (por ejemplo, Ephemeroptera, Odonata, Plecoptera, Trichoptera, Coleoptera y familias selectas de Diptera). Otros trabajos, de interés neártico, complementan también dicha base taxonómica (por ejemplo, Wiggins, 1996). Existen trabajos dispersos de aspectos ecológicos, pero algunas obras más generales han empezado a surgir (Quiroz Martínez y Rodríguez Castro, 2006; Novelo Gutiérrez y Alonso Eguía Lis, 2007).

Como crítica menor, puede mencionarse que es un libro difícil de manipular dado su volumen y flexibilidad, pues está impreso en papel delgado, pero ayuda que está encuadernado en espiral, por lo cual puede darse vuelta totalmente a las páginas. Quizá podría separarse en partes, de acuerdo con los capítulos más utilizados por los diferentes usuarios. Resulta algo incómodo llevarlo a un laboratorio de campo, aunque la regla en la contraportada denota sus orígenes como un recurso primordialmente taxonómico. El libro incluye un CD con una clave interactiva elaborada en la plataforma Lucid, el cual funciona tanto en PC como Mac. La clave sólo llega al nivel de orden, pero se espera que en futuras ediciones incluya también algunas claves a familia; las ilustraciones, dibujos y fotos, son de alta calidad. El CD especifica requerimientos de Windows 98, ME o XP; y Mac OS X 10.1-10.3; no obstante, se puso a prueba en una PC con Windows Vista Home Basic y en una Mac con sistema operativo 10.4.11 y en ambas funcionó sin problema. La clave incluye diversas opciones, con un mínimo de texto, que en conjunto facilitan ampliamente la identificación a orden de ejemplares en cualquier estado de desarrollo (larvas, ninfas, pupas y adultos).

Dado que el campo de la entomología acuática, que incluye sistemática, ecología e historia natural, así como aspectos aplicados como el monitoreo ambiental y los indicadores biológicos, debe tomar un papel crucial por la actual crisis de recursos hídricos, un libro como el flamante "Merrit y Cummins" es un recurso extraordinario. En los ecosistemas de agua dulce, los insectos son un componente conspicuo y abundante, importante en cadenas alimenticias, flujo de energía y reciclamiento de materiales. Por otra parte, algunas especies transmisoras de enfermedades, como los mosquitos, pasan su estado larval en el medio acuático, por lo cual hay un nexo con la entomología médica. Para fortuna de estudiantes, entomólogos, ecólogos, limnólogos, conservacionistas, ingenieros del agua y monitores de la calidad del agua, entomólogos forenses y de todos los interesados en los insectos acuáticos, está ya disponible la cuarta edición del clásico libro, ahora de Merritt, Cummins y Berg.

(Disponible por \$124.95 dl. en www.kendallhunt.com)

\section{Literatura citada}

Arce-Pérez, R. y E. Roughley. 1999. Lista anotada y claves para los Hydradephaga (Coleoptera: Adephaga: Dytiscidae, 
Noteridae, Haliplidae, Gyrinidae) de México. Dugesiana 6:69-104

Contreras-Ramos, A. 1997. Clave para la determinación de los Megaloptera (Neuropterida) de México. Dugesiana 4:51-61.

Edmondson, W. T. (ed.). 1959. Fresh-water biology. John Wiley \& Sons, New York. 1248 p.

Edmunds, G. F., Jr. S. L. Jensen y L. Berner. 1976. The mayflies of North and Central America. University of Minnesota Press, Minneapolis. $330 \mathrm{p}$.

Glenner, H., P. F. Thomsen, M. B. Hebsgaard, M. V. Sørensen y E. Millerslev. 2006. The origin of insects. Science 314:18831884.

Hurlbert, S. H. y A. Villalobos-Figueroa (eds.). 1982. Aquatic biota of Mexico, Central America and the West Indies. San Diego State University, California. 529 p.

Lehmkuhl, D. M. 1979. How to know the aquatic insects. Wm. C. Brown, Dubuque. 168 p.

Llorente Bousquets, J., A. N. García Aldrete y E. González Soriano (eds.). 1996. Biodiversidad, taxonomía y biogeografía de artrópodos de México: hacia una síntesis de su conocimiento. Universidad Nacional Autónoma de México, México, D. F. $660 \mathrm{p}$.

Llorente Bousquets, J., E. González Soriano y N. Papavero (eds.). 2000. Biodiversidad, taxonomía y biogeografía de artrópodos de México: hacia una síntesis de su conocimiento, vol. II. Universidad Nacional Autónoma de México, México, D. F. 676 p.

Llorente Bousquets, J., J. J. Morrone (eds.). 2002. Biodiversidad, taxonomía y biogeografía de artrópodos de México: hacia una síntesis de su conocimiento, vol. III. Universidad Nacional Autónoma de México, México, D. F. 690 p.
Llorente Bousquets, J., J. J. Morrone, O. Yáñez Ordóñez e I. Vargas Fernández (eds.). 2004. Biodiversidad, taxonomía y biogeografía de artrópodos de México: hacia una síntesis de su conocimiento, vol. IV. Universidad Nacional Autónoma de México, México, D. F. 790 p.

McCafferty, W. P., C. R. Lugo-Ortiz, A. V. Provonsha y T.-Q. Wang. 1997. Los efemerópteros de México: I. Clasificación superior, diagnosis de familias y composición. Dugesiana $4: 1-29$.

Novelo-Gutiérrez, R. 1997a. Clave para la separación de familias y géneros de las náyades de Odonata de México. Parte I. Zygoptera. Dugesiana 4:1-10.

Novelo-Gutiérrez, R. 1997b. Clave para la determinación de familias y géneros de las náyades de Odonata de México. Parte II. Anisoptera. Dugesiana 4:31-40.

Novelo-Gutiérrez, R. y P. Alonso-Eguía Lis (eds.). 2007. Simposio Internacional Entomología Acuática Mexicana: estado actual de conocimiento y aplicación. Instituto Mexicano de Tecnología del Agua, Sociedad Mexicana de Entomología, Jiutepec, Morelos. 105 p.

Pennak, R. W. 1978. Fresh-water invertebrates of the United States, segunda edición, John Wiley \& Sons, New York. 803 p.

Quiroz Martínez, H. y V. A. Rodríguez Castro (eds.). 2006. Bioindicadores de contaminación en sistemas acuáticos (insectos acuáticos). Universidad Autónoma de Nuevo León, Monterrey. 96 p.

Usinger, R. L. (ed.). 1956. Aquatic insects of California. University of California Press, Berkeley. 508 p.

Wiggins, G. B. 1996. Larvae of the North American caddisfly genera (Trichoptera), 2da ed. University of Toronto Press, Ontario. 457 p. 